\title{
Strategies for the prevention of psychiatric disorder in primary care in south London
}

\author{
Scott Weich, Glyn Lewis, Rachel Churchill, Anthony Mann
}

\begin{abstract}
Study objective-To compare the potential impact of high risk and population based approaches to the prevention of psychiatric disorder, using a representative sample of general practice attenders as the target population.
\end{abstract}

Design-This was a prospective cohort study.

Setting-A health centre in south London. Participants-Three hundred and seven consecutive attenders aged 16-65, recruited at randomly selected general practice surgeries.

Main results-A linear association was found between the number of different types of socioeconomic adversity reported at recruitment (T1) and the prevalence of psychiatric disorder one year later (T2). The population attributable fraction (PAF) for socioeconomic adversity at T1 was $37.4 \%$. In theory, social interventions for high risk individuals at $\mathrm{T} 1$ would reduce the prevalence of psychiatric disorder at $\mathrm{T} 2$ by $9 \%$ at most, compared with a reduction of $18 \%$ if just one item of socioeconomic adversity were eliminated among those with any socioeconomic risk factors.

Conclusions-Social interventions targeted at individuals at highest risk of the most common mental disorders are likely to be extremely limited in their capacity to reduce the prevalence of these conditions. A population based risk reduction strategy, modified according to individual risk, represents a potentially feasible and effective alternative.

( $(\mathcal{E}$ Epidemiol Community Health 1997;51:304-309)

Section of

Epidemiology and General Practice, Institute of Psychiatry, De Crespigny Park, London SE5 8 AF $S$ Weich

$\mathrm{R}$ Churchill

A Mann

University of Wales College of Medicine, Cardiff

G Lewi

Correspondence to: $\operatorname{Dr} S$ Weich, University Department of Psychiatry, Royal Free Hospital School of Medicine, Rowland Hill of Medicine, Rowland Hill

Accepted for publication September 1996
A strong argument exists for developing strategies to reduce the prevalence of the most common mental disorders, anxiety and depression. These conditions have a combined prevalence rate in the community of between $15 \%$ and $30 \%,{ }^{1-5}$ and account for one third of days lost from work due to ill health ${ }^{6}$ and one fifth of consultations in general practice in the UK. ${ }^{7}$ The public health importance of these disorders, even in mild form, is further shown by the finding that low levels of depression resulted in $51 \%$ more days lost from work than major depression. ${ }^{8}$ The annual cost of the common mental disorders in the UK may amount to $£ 6$ billion, of which two thirds results from lost productivity. ${ }^{9}$ Ominously, their prevalence may have increased recently. ${ }^{10}$
The most common preventive approach in psychiatry involves targeting individuals at high risk of disorder, ${ }^{11-14}$ which Rose ${ }^{15}$ likened to, "attempting to control icebergs by sending warships to shoot off their visible portions". Psychiatrists often reject population based interventions, partly through aetiological uncertainty $^{15}$ and partly because these are perceived as either inefficient ${ }^{13}$ or synonymous with utopian political change. ${ }^{16}$ Many would concur with Goldberg's view that, "it is intuitively easy to see that it would be wasteful to devote resources to populations who are unlikely to get depressed". ${ }^{13}$

A recent report commissioned by the US Congress argued for a population based risk reduction approach. ${ }^{17}$ The common mental disorders are associated with forms of socioeconomic adversity that could possibly be corrected, including low income and financial hardship, ${ }^{18-22}$ unemployment, ${ }^{23}$ poor housing, ${ }^{24-28}$ lack of education, ${ }^{29}$ and social isolation. ${ }^{22}$ In randomised trials, risk factors and (in some cases) the prevalence of common mental disorders have been reduced by interventions to address unemployment, ${ }^{30}$ marital separation, ${ }^{31}$ bereavement, ${ }^{32}$ and teenage pregnancy in the context of socioeconomic deprivation. ${ }^{33}$ Such interventions could form the basis of a risk reduction package. Primary care, where up to $40 \%$ of attenders suffer from the common mental disorders, ${ }^{34}$ represents an attractive setting in which to evaluate their potential effectiveness. Only one previous study has evaluated a preventive intervention (training in cognitive behavioural skills) aimed at a population of general practice attenders. ${ }^{34}$ This study was restricted to preventing incident cases of depression and failed to produce statistically significant findings because of the rarity of this outcome.

This study aims to add data to what is often a polemical debate. Its objective is to compare the potential impact of high risk and population based approaches to the prevention of psychiatric disorder, using a representative sample of general practice attenders as the target population.

\section{Methods}

A prospective cohort study was conducted at a health centre in south London. Study methods have been described elsewhere. ${ }^{35}$ Consecutive attenders aged 16-65 years were recruited at randomly selected surgeries. Subjects completed a questionnaire comprising the 12 item general health questionnaire (GHQ-12) ${ }^{36}$ and a checklist of recent somatic symptoms before 
being approached for baseline interview (T1). Those who completed this interview were approached for a further interview 12 months later (T2).

The interview assessments were the following:

- The computer administered clinical interview schedule (CIS-R), ${ }^{373}$ using a case threshold of $11 / 12$,

- A computer administered social assessment covering marital status, children, education, employment, personal finances, housing, and physical handicap.

In the social assessment, low income was defined as an adjusted ${ }^{39}$ household income below the lowest quartile for the sample. Structural housing problems were defined as one or more of damp, rot in woodwork or infestation. Overcrowding was defined as living in a household where the ratio of people:bedrooms was greater than 2. Physical disability was defined as a physical impairment that interfered with activities of daily living.

Social assessment data were used to construct an 11 item index of current socioeconomic adversity (ICSA-11). Items were forms of objective socioeconomic adversity judged a priori by the investigators to involve unequivocal hardship, and which were thought to be potentially remediable. An ICSA-11 score was derived by scoring one point for each type of socioeconomic adversity. A shortened version of the ICSA-11 (the ICSA-2, see Results) was produced by restricting variables to those that were independently associated with being a case of psychiatric disorder at T2, after adjusting for the ten other ICSA-11 items.

\section{STATISTICAL ANALYSES}

Unadjusted odds ratios ( $95 \%$ confidence intervals) for each ICSA-11 item were compared with those adjusted for the other 10 items using logistic regression. Likelihood ratio tests were used to compare linear with categorical models and to test for interactions. Analyses were performed using Stata. ${ }^{40}$

The population attributable fraction (PAF) is an estimate of the proportion of cases at T2 attributable to socioeconomic adversity at $\mathrm{T} 1$, and therefore the proportion of cases that could be prevented, in theory, if the association in question is not confounded by other risk factors, if the exposure in question were removed, and if in doing so other risk factors remained constant. PAFs were calculated using risk ratios derived from logistic regression coefficients. Since the prevalence of common mental disorder was too great to satisfy the rare disease assumption, odds ratios were numerically greater than corresponding risk ratios and would have led to overestimates of respective PAFs. In general, for an exposure with multiple levels, the fraction of cases attributable to exposure at level $\mathrm{k}$ may be calculated by:

$$
\operatorname{PAF}_{k}=p_{k}{ }^{\prime}\left(\theta_{k}-1\right) / \theta_{k}
$$

where $p_{k}{ }^{\prime}$ is the proportion of cases at exposure level $\mathrm{k}$ and $\theta_{\mathrm{k}}$ is the risk ratio for individuals exposed to level $\mathbf{k}$ (compared with the baseline group). For example, at ICSA-11 score $\geq 4$ :

$$
\mathrm{PAF}=0.142(2.46-1) / 2.46=0.084
$$

Alternatively, the PAF at each level of ICSA score may be estimated by calculating the proportion of cases at T2 that could be prevented (in theory) by reducing the ICSA score to 0. The number of cases that might be prevented by incremental reductions in the ICSA score was calculated as the sum of the differences between the observed number of cases at each level of exposure (eg ICSA-11 score $\geq 4$ ) and the expected number of cases for the same subjects if their individual risk (ie the risk ratio) of psychiatric disorder at T2 were reduced to that of subjects in the adjacent stratum (eg ICSA-11 score = 3). Numbers of expected cases were calculated by multiplying the number of subjects at the higher level of exposure (eg ICSA-11 score $\geq 4$ at $\mathrm{T} 1$ ) by the risk ratio for subjects at the next lowest level of exposure (eg risk ratio for subjects with ICSA-11 score= 3), and then multiplying this figure by the proportion of cases at the baseline level of exposure (ie ICSA-11 score $=0$ ). For example, the number of cases prevented by a one point reduction in ICSA-11 score among subjects with a score of $\geq 4$ at $\mathrm{T} 1$ was calculated thus:

$$
\text { Observed cases }- \text { expected cases }=
$$$$
15-(24 \times 2.08 \times 0.254)=2.32 \text { cases }
$$

This calculation was done for all levels of ICSA-11 score at T1. The sum of the differences between observed and expected numbers of cases was then divided by the total number of cases at T2, and expressed as a percentage reduction in the prevalence of psychiatric disorder. Finally, the potential impact of social interventions on the prevalence of psychiatric disorder at T2 was estimated for two (hypothetical) target groups as follows:

- A group at high social risk at $\mathrm{T} 1$, defined as an ICSA-11 score $\geq 4$ (or ICSA-2 score $=$ 2),

- Subjects with any social risk, defined as an ICSA-11 (or ICSA-2) score $\geq 1$.

\section{Results}

Of 426 attenders who were approached, 404 (94.8\%) completed the preliminary questionnaire, $307(72.1 \%)$ completed the first interview (T1), and 261 were re-interviewed 12 months later (T2) - a follow up rate of $85.0 \%$. No statistically significant differences were found between those who did and did not participate at $T 1$ in respect of age, sex, GHQ score, or somatic symptom score. Subjects lost to follow up did not differ to a statistically significant degree from those who completed the $T 2$ interview in respect of age, sex, or either ICSA-11 or CIS-R scores at T1. Of those who completed both interviews, $168(64.4 \%, 58.6$, 70.2) were women. At T2, 106 subjects were cases of psychiatric disorder, a prevalence rate of $40.6 \%(34.6,46.6)$. The estimated annual incidence rate for psychiatric disorder was $15.7 \%(10.5,23.4)$, and the annual rate of 
Table 1 Prevalence of exposure and adjusted odds ratios (OR) (95\% confidence intervals) for being a case at one year follow up (T2) in relation to each of the variables included in the index of current socioeconomic adversity (ICSA-11) assessed at recruitment (T1), and OR adjusted for each of the other variables in the table

\begin{tabular}{|c|c|c|c|c|c|}
\hline \multirow[b]{2}{*}{ Variable } & \multirow[b]{2}{*}{$\%$ exposed (no) } & \multicolumn{2}{|l|}{ Unadjusted $O R$} & \multicolumn{2}{|l|}{ Adjusted $O R$} \\
\hline & & $(95 \% C I)$ & $p$ & $(95 \% C I)$ & $p$ \\
\hline Single parent & $7.3(19)$ & $3.47(1.18,11.48)$ & 0.02 & $2.86(0.76,10.82)$ & 0.12 \\
\hline Low income & $23.7(62)$ & $3.54(1.86,6.75)$ & $<0.0001$ & $2.68(1.22,5.86)$ & 0.01 \\
\hline Structural housing problems & $24.9(65)$ & $2.69(1.46,4.98)$ & 0.001 & $2.07(1.07,4.03)$ & 0.03 \\
\hline Overcrowding & $1.9(5)$ & $0.98(0.08,8.74)$ & 1.00 & $1.53(0.24,9.95)$ & 0.66 \\
\hline No educational qualifications & $42.0(129)$ & $1.45(0.85,2.47)$ & 0.18 & $1.26(0.66,2.38)$ & 0.49 \\
\hline Physical handicap & $7.7(20)$ & $1.29(0.47,3.53)$ & 0.76 & $1.14(0.40,3.26)$ & 0.81 \\
\hline Unemployed (self) & $15.3(40)$ & $0.86(0.40,1.80)$ & 0.79 & $0.99(0.02,5.45)$ & 0.98 \\
\hline Seperated/divorced/widowed & $13.7(42)$ & $1.66(0.80,3.48)$ & 0.20 & $0.97(0.39,2.40)$ & 0.95 \\
\hline Partner/spouse unemployed & $7.3(19)$ & $1.35(0.48,3.74)$ & 0.70 & $0.94(0.31,2.90)$ & 0.92 \\
\hline Debt $\geq £ 1000$ & $15.3(40)$ & $0.97(0.46,2.03)$ & 1.00 & $0.94(0.42,2.09)$ & 0.87 \\
\hline Homeless & $0.8(2)$ & $1.47(0.02,115.9)$ & 1.00 & $0.43(0.02,11.27)$ & 0.61 \\
\hline
\end{tabular}

maintenance (ie non-remission) of psychiatric disorder was $68.8 \%(57.6,77.1) .{ }^{35}$ Psychiatric disorder at T2 was associated with a higher somatic symptom score at index consultation $(\mathrm{p}<0.001)$ and older age $(\mathrm{p}=0.04)$.

\section{SOCIOECONOMIC ADVERSITY AND PSYCHIATRIC DISORDER}

The frequency of exposure to ICSA-11 items ranged from $42.0 \%$ (no educational qualifications) to $0.8 \%$ (homelessness), and (unadjusted) odds ratios for psychiatric disorder at $\mathrm{T} 2$ ranged from $3.54(1.86,6.75)$ (low income) to $0.86(0.40,1.80)$ (subject unemployed). After adjusting for other ICSA-11 items, only low income and structural housing problems remained independently associated with psychiatric disorder at T2. These two items formed the ICSA-2 (table 1).

Statistically significant linear trends were identified between psychiatric disorder at T2 and both ICSA-11 score $\left(\chi^{2}\right.$ for linear trend $=$ $14.15, \mathrm{df}=1, \mathrm{p}=0.0002 ; \chi^{2}$ for departure from linear trend $=0.21, \mathrm{df}=3, \mathrm{p}=0.98$ ) and ICSA2 score $\left(\chi^{2}\right.$ for departure from linear trend $=$ $1.11, \mathrm{df}=1, \mathrm{p}=0.29$ ). Adjusting for CIS-R score at $\mathrm{T} 1$ did not alter the linearity of these associations, and had only a small effect on their size, reducing the odds ratio for ICSA-11 score from $1.48(1.20,1.81)$ to 1.30 (1.01, 1.68 ), and that for ICSA-2 from 2.72 (1.80, $4.11)$ to $2.33(1.41,3.83)$. A statistically significant positive correlation was found between ICSA-11 score and age $(\mathrm{r}=0.32, \mathrm{p}<0.001)$, but not with somatic symptom score at index consultation $(p=0.58)$. Age did not confound the association between ICSA-11 score and psychiatric disorder at $\mathrm{T} 2$ to a statistically significant extent.

\section{THE POTENTIAL IMPACT OF PREVENTIVE}

STRATEGIES

The total PAF for all socioeconomic adversity as assessed by the ICSA-11 was $37.4 \%$, of which $8.4 \%$ was attributable to the highest category of social risk (ICSA-11 $\geq 4$ ). Analysis using ICSA-2 scores yielded similar findings (table 2).

Table 3 contrasts the potential impact of interventions targeted at the entire population of attenders on the one hand, and at those with the highest ICSA-11 scores. In theory, a one point reduction in ICSA-11 score among those at high social risk (ICSA-11 $\geq 4$ ) would result in a $2.2 \%$ reduction in the prevalence of psychiatric disorder at T2, compared with $18.0 \%$ if the ICSA-11 score of all attenders who scored 1 or more on this measure were reduced by the same amount. If all socioeconomic adversity were removed, the maximum predicted reduction in prevalence that could be achieved by the high risk approach would be $8.4 \%$ using ICSA-11 (or $8.3 \%$ using ICSA-2), compared with a $37.4 \%$ reduction $(30.6 \%$ using ICSA2) if all those with any socioeconomic risk factors were targeted.

High risk for a continuous exposure may be defined by placing the cut off point anywhere along the continuum of risk. Figure 1 shows that the potential reduction in the prevalence of psychiatric disorder at T2 arising from interventions at $\mathrm{T} 1$ is directly proportional to the number of subjects eligible for intervention.

\section{Discussion}

The prevalence of psychiatric disorder at $\mathrm{T} 2$ $(40.6 \%)$ was higher than in comparable primary care studies. ${ }^{41-43}$ This was unlikely to be due to measurement artefact or bias, since

Table 2 Distribution of study sample and the revised clinical interview schedule (CIS-R) cases at one year follow up (T2), risk ratio (RR) (95\% confidence interval (CI)), and population attributable fraction (PAF) in relation to longer and shorter versions of the index of current socioeconomic adversity (ICSA-11 and ICSA-2, respectively) scores at recruitment (T1)

\begin{tabular}{|c|c|c|c|c|c|c|c|c|}
\hline \multirow{2}{*}{$\begin{array}{l}\text { ICSA } \\
\text { score at } T 1\end{array}$} & \multicolumn{4}{|c|}{ ICSA-11 (range $0-4)$} & \multicolumn{4}{|c|}{ ICSA-2 (range $0-2$ ) } \\
\hline & $\%$ sample (no) & $\%$ of $T 2$ cases (no) & $R R(95 \% C I)$ & $P A F \%$ & $\%$ sample (no) & $\%$ of $T 2$ cases (no) & $R R(95 \% C I)$ & $P A F \%$ \\
\hline 0 & $24.1(63)$ & $15.1(16)$ & 1.00 & - & $59.8(156)$ & $41.5(44)$ & 1.00 & - \\
\hline 1 & $29.5(77)$ & $25.4(28)$ & $1.43(0.85,2.40)$ & 7.9 & $31.8(83)$ & $44.3(47)$ & $2.01(1.47,2.75)$ & 22.3 \\
\hline 2 & $23.4(61)$ & $26.4(28)$ & $1.81(1.09,2.99)$ & 11.8 & $8.4(22)$ & $14.2(15)$ & $2.42(1.65,3.53)$ & 8.3 \\
\hline 3 & $13.8(36)$ & $17.9(19)$ & $2.08(1.23,3.51)$ & 9.3 & - & - & - & - \\
\hline$\geq 4$ & $9.2(24)$ & $14.2(15)$ & $2.46(1.46,4.16)$ & 8.4 & 一 & - & - & - \\
\hline Totals & $100(261)$ & $100(106)$ & $1.79(1.14,2.81)^{*}$ & $37.4 \dagger$ & $100(261)$ & $100(106)$ & $2.09(1.56,2.82)^{*}$ & $30.6 \dagger$ \\
\hline
\end{tabular}

* RR for any socioeconomic adversity (ICSA score $\geq 1$ )

† Total PAF for all socioeconomic adversity in study population. 
Table 3 Predicted potential reduction in the prevalence of psychiatric disorder at one year follow up (T2) resulting from "high risk" and "population based" social interventions in relation to incremental reductions in the longer and shorter versions of the index of current socioeconomic adversity (ICSA-11 and ICSA-2 respectively) score among those targeted for intervention. The final row indicates the proportion of the study sample who would have been eligible for the intervention (s)

\begin{tabular}{|c|c|c|c|c|}
\hline \multirow{2}{*}{$\begin{array}{l}\text { Reduction in ICSA } \\
\text { score in target group }\end{array}$} & \multicolumn{2}{|c|}{ ICSA-11 (range 0-4) } & \multicolumn{2}{|c|}{ ICSA-2 (range 0-2) } \\
\hline & High risk* & Population $\dagger$ & High risk $\ddagger$ & Population \$ \\
\hline $\begin{array}{l}-1 \\
-2 \\
-3 \\
-4 \\
\% \text { attenders eligible }\end{array}$ & $\begin{array}{l}2.2 \\
3.7 \\
5.9 \\
8.4 \\
9.2\end{array}$ & $\begin{array}{l}18.0 \\
29.1 \\
35.0 \\
37.4 \\
75.9\end{array}$ & $\begin{array}{l}2.4 \\
8.3 \\
\frac{-}{7.1}\end{array}$ & $\begin{array}{l}24.7 \\
30.6 \\
\overline{-} \\
40.1\end{array}$ \\
\hline
\end{tabular}

* ICSA-11 score $\geq 4$; † All subjects with ICSA-11 score $\geq 1$; $¥$ ICSA-2 score $=2$; $\$ All subjects with ICSA-2 score $\geq 1$.

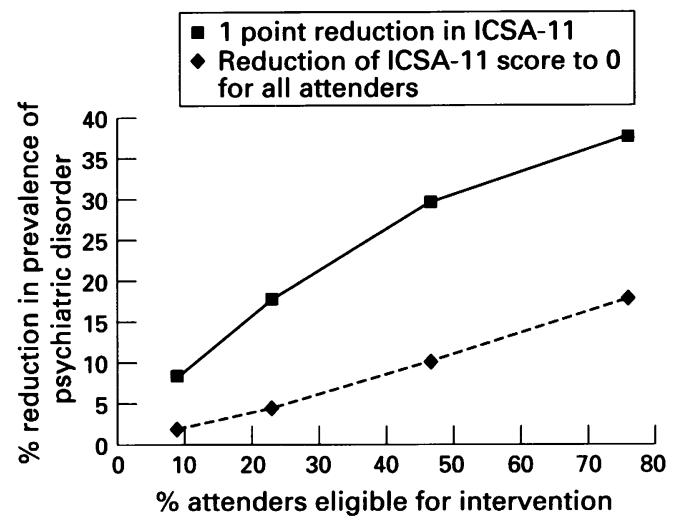

Figure 1 The potential reduction in the prevalence of psychiatric disorder at one year follow up (T2) arising from (1) a one point reduction in the index of current socioeconomic adversity (ICSA-11) score and (2) a reduction in the ICSA-11 to 0 for all eligible subjects against the percentage of attenders eligible for intervention.

the CIS- $R$ has recently been validated in a community survey, ${ }^{5}$ and the 12 month incidence rate was similar to that found elsewhere. ${ }^{44}$ The high prevalence of psychiatric disorder was most likely to reflect the inner city setting of the study practice, ${ }^{35}$ and is unlikely to have influenced either the magnitude or linearity of the association between socioeconomic adversity and psychiatric disorder.

Physical illness was a potential confounder. Despite including physical handicap as a type of socioeconomic adversity (since handicap may be remediable even if the underlying disability is not), we did not find a statistically significant association between the ICSA-11 score and somatic symptom score at T1. Although the severity of somatic symptoms at index consultation did not therefore confound the association of interest, we cannot exclude the possibility of residual confounding by other indices of physical ill health.

PREVENTION OF THE COMMON MENTAL DISORDERS

Our results are consistent with previous evidence of associations between rates of common mental disorders and both low income 18-2224 and poor housing. ${ }^{24-28}$ Previous findings from this study show that while socioeconomic variables such as low household income were associated with a worse outcome among prevalent cases at baseline, such variables were only weakly associated with the incidence of psychiatric disorder after adjusting for potential confounders. By contrast, family psychiatric history and the severity of psychiatric symptoms at $\mathrm{T} 1$ were independently associated with the incidence psychiatric disorder after adjusting for other risk factors, including measures of previous psychiatric disorder. ${ }^{35}$ Thus, socioeconomic interventions may be of greater importance in secondary than primary prevention.

As expected, most cases of psychiatric disorder at T2 occurred in individuals at low social risk at $\mathrm{T} 1 .^{45}$ The association between ICSA11 score at $\mathrm{T} 1$ and the prevalence of psychiatric disorder at T2 was linear and, as figure 1 shows, the potential predicted reduction in the prevalence of psychiatric disorder achievable by socioeconomic interventions was directly proportional to the proportion of attenders targeted for intervention. Thus, interventions targeted at those with the highest social risk in this study (defined as an ICSA-11 score $\geq 4$ ) are likely to be extremely limited in their impact on the prevalence of psychiatric disorder, since only $9 \%$ of attenders fell into this category. At the other extreme, it was predicted that $18 \%$ of cases at T2 could have been prevented, in theory, if the ICSA-11 scores of the three quarters of attenders with a score of 1 or more at $\mathrm{T} 1$ were reduced by just one point.

There are three important caveats. Firstly, the findings are population specific. While the risk ratio is likely to remain constant across populations, the incidence and maintenance rates and the PAF will decline as exposure to socioeconomic adversity falls. The incidence and maintenance of common mental disorders will be lower in less socially deprived areas, and a smaller proportion of all cases will be attributable to socioeconomic adversity. Secondly, we have assumed that effective interventions exist to remove the socioeconomic adversity covered by our index, and that such interventions would reduce the prevalence of psychiatric disorder 12 months later. While we can calculate the maximum potential impact of such interventions, these figures are hypothetical. Clearly, other studies are needed to assess the actual effects of specific interventions. Finally, members of the study population were likely to be at higher risk of psychiatric disorder than individuals living in more affluent areas. In restricting our sample to those attending a single health centre in south London, we have compared the potential impact of high risk and population based approaches to prevention nested within a high risk approach. While this does not affect the validity of our findings, it further highlights the need for caution in generalising these findings beyond similar inner city settings.

Preventive interventions are specific to disorder and depend partly on the shape of the dose-response relationship between the exposure and risk of disorder. A population based approach is likely to have the greatest impact where this is linear, or where the risk of disorder plateaus above a certain level of exposure. By contrast, a high risk approach would be more 
appropriate where the risk of disorder increases sharply above a certain level of exposure (ie a threshold effect). Where the dose-response curve is linear, the decision about what proportion of a population should be targeted for intervention will depend on the availability and acceptability of effective intervention, ${ }^{46}$ and the associated costs and benefits. The fundamental dilemma, however, is that while the benefits of a population intervention may outweigh its costs, and may greatly exceed the absolute benefits of an intervention restricted to those at the highest risk of disorder, the absolute cost of intervention is likely to be high.

High risk interventions may bring great benefit to the small number of individuals at the highest risk of developing a specific disorder and are an important part of good clinical practice. Although we have compared the (theoretical) impact of high risk and population wide interventions, these are best conceptualised as the extremes of a continuum. As Rose and Lewis pointed out, ${ }^{47}$ these strategies should be viewed as complementary components of a needs-led, population based prioritised system of comprehensive risk factor control.

\section{CONCLUSIONS}

A high risk approach to prevention alone is incapable of meeting the public health challenge of reducing the prevalence of the most common mental disorders. ${ }^{4548}$ Nevertheless, it might be argued that low income and structural housing problems are intractable forms of socioeconomic adversity, and that a high risk approach represents the most pragmatic use of limited resources. ${ }^{1314}$ What are the alternatives? Egalitarian political interventions, such as changes in taxation or housing policy, ${ }^{4849}$ are likely to be opposed because they are costly and as yet unsupported by empirical evidence. If population based interventions are to gain credibility, interventions must be developed which are both economically feasible and acceptable to populations. ${ }^{46}$ Unfortunately, it is not clear what form these should take. There have been no trials of interventions designed to alleviate low income or housing problems, and nor do we know whether it would be more effective to address such fundamental socioeconomic causes or individual characteristics, such as interpersonal relationships or cognitive style, which may mediate their effect on mental health. ${ }^{50}$ Further research is needed to identify mediating risk factors, and to explore the feasibility and acceptability of alternative interventions.

Experience from community trials of cardiovascular prevention shows clearly that such interventions must be "owned" locally, since their effectiveness depends on their acceptability to the target population. To this end members of the community, along with its leaders and institutions, must be mobilised during the design phase of any intervention. ${ }^{46}$ We suggest that a locally tailored, multi-domain package of risk reduction measures might be developed, in collaboration with users, GPs, public health physicians, community leaders, local authority social services and housing departments, voluntary organisations, and the local media. ${ }^{1747}$ The ultimate form of the intervention would be determined by both aetiological evidence and local need, and might involve education via the media, plus individual level programmes to provide, for example, advice and advocacy in securing benefits, managing personal finances, and negotiating housing repairs.

This study was funded by the NHS Executive Computer R\&D fund. We are indebted to the staff and patients of the Albion Street Health Centre, Rotherhithe, for their support and cooperation with this study. We are especially indebted to Dr Richard Donmall for facilitating this collaboration. We are grateful to Professor Eugene Paykel for his helpful comments grateful to Professor Eugene Payk
on an earlier draft of this paper.

1 Cox BD, Blaxter M, Buckle ALJ, et al. The health and lifestyle survey. Cambridge: Health Promotion Research Trust, 1987.

2 Robins LN, Regier DA, eds. Psychiatric disorders in America: the epidemiological catchment area study. New York: The Free Press, 1991:449.

3 Goldberg D, Huxley P. Common mental disonders: a biopsychosocial approach. Routledge: London, 1992.

4 Kessler RC, McGonagle KA, Zhao S, et al. Lifetime and 12-month prevalence of DSM-III-R psychiatric disorders 12-month prevalence of DSM-III-R psychiatric disorders
in the United States. Arch Gen Psychiatry 1994;51:8-19. in the United States. Arch Gen Psychiatry 1994;51:8-19.
Meltzer H, Gill B, Petticrew M. OPCS surveys of psychiatric morbidity in Great Britain. Report No 1. The prevalence of psychiatric morbidity among adults aged 16-64 living in private households in Great Britain. London: HMSO, 1995.

6 Jenkins R. Minor psychiatric disorder in employed young men and women and its contribution to sickness absence. Br F Ind Med 1985;42:147-54

7 Williams P, Tarnopolsky A, Hand D, Shepherd M. Minor psychiatric morbidity and general practice consultations: the west London survey. Psychol Med 1986; Monograph Supp1 9:1-37.

8 Broadhead WE, Blazer D, George L, Tse C. Depression, disability days and days lost from work. $¥ A M A 1990 ; 264$ : 2524-28.

9 Croft-Jefferys C, Wilkinson G. Estimated costs of neurotic disorder in UK general practice. Psychol Med 1989;19: disorder

10 Lewis G, Wilkinson G. Another British disease? A recent increase in the prevalence of psychiatric morbidity in Britain. F Epidemiol Community Health 1993;47:358-61

11 Harris $T$. Implications of a vulnerability model for the prevention of affective disorder. In: Cooper B, Helgason $\mathrm{T}$, eds. Epidemiology and the prevention of mental disorders. London: Routledge, 1989:207-27.

12 Jenkins R. Depression and anxiety: an overview of preventive strategies. In: Jenkins R, Newton J, Young R, eds. The prevention of anxiety and depression. London: HMSO, 1992: 11-21.

13 Goldberg D. Early diagnosis and secondary prevention. In: Jenkins $\mathrm{R}$, Newton J, Young R, eds. The prevention of anxiety and depression. London: HMSO, 1992:33-38.

14 Paykel ES, Jenkins R, eds. Prevention in psychiatry. London: Gaskell, 1994.

15 Rose G. Mental disorder and the strategies of prevention. Psychol Med 1993;23:553-55.

16 Scott J, Leff J. Social factors, social interventions and prevention. In: Paykel ES, Jenkins R, eds. Prevention in psychiatry. London: Gaskell, 1994:25-31.

17 Mrazek PJ, Haggerty RJ, eds. Reducing risks for mental disorders. Washinton, DC: National Academy Press, 1994.

18 Bruce ML, Takeuchi DT, Leaf PJ. Poverty and psychiatric status. Arch Gen Psychiatry 1991;48:470-474.

19 Murphy JM, Olivier DC, Monson RR, Sobol AM, Federman $\mathrm{EB}$, Leighton AH. Depression and anxiety in relation to social status. Arch Gen Psychiatry 1991;48:223-29. $20 \begin{gathered}\text { Rodgers B. Socio-economic status, employment and neur- } \\ \text { osis. Soc Psychiatry Psychiatr Epidemiol 1991;26:104-14. }\end{gathered}$

21 Romans SE, Walton VA, McNoe B, Herbison GP, Mullen $\mathrm{PE}$. Otago women's health survey 30 month follow-up. II: remission patterns of non-psychotic psychiatric disII: remission patterns of non-psychotic
order. Br $\mathcal{F}$ Psychiatry 1993;163:739-46.

22 Bruce ML, Hoff RA. Social and physical health risk factors for first-onset major depressive disorder in a community for first-onset major depressive disorder in a community 71 .

23 Warr P. Work, unemployment and mental health. Oxford: Oxford Science Publications, 1987:1-361.

24 Platt S, Martin C, Hunt S. The mental health of women with children living in deprived areas of Great Britain: the role of living conditions, poverty and unemployment. In Goldberg D, Tantam D, eds. The public health impact of mental disorder. Toronto: Hogrefe and Huber, 1990. 124-135.

25 Brown GW, Harris T. Social origins of depression. London: Tavistock, 1978.

26 Huxley PJ, Goldberg DP, Maguire GP, Kincey VA. The 
prediction of the course of minor psychiatric disorders. Br F Psychiatry 1979;135:535-43.

27 Birtchnell J, Masters N, Deahl M. Depression and the physical environment: a study of young married women on a London housing estate. $B r \mathcal{F}$ Psychiatry 1988;153:56-64.

28 Goldberg D, Bridges K, Cook D, Evans B, Grayson D. The influence of social factors on common mental disorders: destabilisation and restitution. Br $\mathcal{F}$ Psychiatry 1990;156: 704-13.

29 Blazer DG, Kessler RC, McGonagle KA, Swartz MS. The prevalence and distribution of major depression in a national community sample: the National comorbidity survey. Am $\mathcal{F}$ Psychiatry 1994;151:979-86.

30 Price $\mathrm{RH}$, van Ryn M, Vinokur A. Impact of a preventive job search intervention on the likelihood of depression among the unemployed. $f$ Health Soc Behavior 1992;33: among the

31 Bloom BL, Hodges WF, Kern MB, McFaddin SC. A preventive intervention program for the newly separated. $A m$ f Orthopsychiatry 1985;55:9-26.

32 Vachon MLS, Sheldon AR, Lancee WJ, Lyall WAL, Roger J, Freeman SJJ. A controlled study of self-help intervention for widows. Am $\mathcal{F}$ Psychiatry 1980;137:1380-84.

33 Olds DL, Henderson CR, Tatelbaum R, Chamberlin R. Improving the life-course development of socially disadvantaged mothers: a randomised trial of nurse home visitation. Am 7 Public Health 1988;78:1436-45.

34 Munoz RF. The prevention of depression: current research and practice. Applied and Preventive Psychology 1993;2: 21-33.

35 Weich S, Churchill R, Lewis G, Mann A. Do socio-economic risk factors predict the incidence and maintenance of psychiatric disorder in primary care? Psychol Med 1997; 27:73-80.

36 Goldberg DP, Williams P. The user's guide to the general health questionnaire. Windsor, Berks. Nfer-Nelson, 1988.
37 Lewis G, Pelosi AJ, Araya R, Dunn G. Measuring psychiatric disorder in the community: a standardised assessment for disorder in the community: a standardised assessment
use by lay interviewers. Psychol Med 1992;22:465-86.

38 Lewis G. Assessing psychiatric disorder with a human interviewer or a computer. $\mathcal{F}$ Epidemiol Community Health 1994;48:207-10.

39 Hills J. Inquiry into income and wealth. York: Joseph Rowntree Foundation, 1995

40 Stata Corporation. Stata statistical software: release 4.0. College Station, Texas: Stata Corporation, 1995.

41 von Korff M, Shapiro S, Burke JD, et al. Anxiety and depression in a primary care clinic. Arch Gen Psychiatry 1987;44:152-56.

42 Barrett JE, Barrett JA, Oxman TE, Gerber PD. The prevalence of psychiatric disorders in a primary care practice. Arch Gen Psychiatry 1988;45:1100-6.

43 Ormel J, Koeter MWJ, van den Brink W, van de Willige G. Recognition, management and course of anxiety and depression in general practice. Arch Gen Psychiatry 1991; 48:700-6.

44 Kessler LG, Cleary PD, Burke JD. Psychiatric disorders in primary care. Arch Gen Psychiatry 1985;42:583-87.

45 Rose G. The strategy of preventive medicine. Oxford: Oxford University Press, 1992

46 Koepsall TD, Diehr PH, Cheadle A, Kristal A. Invited commentary: symposium on community intervention trials. Am ₹ Epidemiol 1995;142:594-99.

47 Lewis B, Rose G. Prevention of coronary heart disease: putting theory into practice. $\mathcal{F} R$ Coll Physicians Lond 1991 25:21-26.

48 Watt GCM. All together now: why social deprivation matters to everyone. BMF 1996;312:1026-29.

49 Benzeval M, Judge K, Whitehead M, eds. Tackling inequalities in health. London: King's Fund, 1995.

50 Link BG, Phelan J. Social conditions as fundamental causes of disease. $\mathcal{F}$ Health Soc Behav 1995; (extra issue):80-94. 
3 Bartko JJ. The intraclass correlation coefficient as a measure of reliability. Psychol Rep 1966;19. 3-11.

4 Prieto L, Lamarca R, Casado A. La evaluacion de la fiabilidad en las observaciones clinicas: el Coeficente de Correlacion Intraclase. Med Clin (Barc). In press.

\section{NOTICES}

European Journal of Public Healthvolume 7 (2) June 1997

\section{Editorial}

Balancing state and market in health system reform $R B$ Saltman

\section{Editorial note}

f Palm, P-G Svensson

\section{Original articles}

Use of provocative emotional appeals in a mass media campaign designed to prevent smoking among adolescents. $A$ Hafstad, $B$ Stray-Pedersen, $F$ Langmark

Managing the gap between demand and publicly affordable health care in an ethical way. $\mathcal{F} A$ Öretveit

Measuring performance in hospital care: length of stay in gynaecology. $A H$ Leyland, FA Boddy

Adolescent motherhood and socioeconomic factors: an ecologic approach. M Nebot, $C$ Borrell, $\mathcal{F} R$ Villalbi

Impaired cognitive function in elderly men exposed to benzodiazepines or other anxiolytics. F Ranstam, $\mathcal{F}$ Merlo, $G$ Blennow, $B S$ Hanson, $\mathrm{P}-\mathrm{O}$ Östergren, $A$ Melander

Cost-effectiveness of vaccination against pneumococcal pneumonia in the Netherlands. $R M P M$ Baltussen, $A \mathcal{F} H A$ Ament, $R$ $M$ Leidl, $R$ van Furth

Sick-leave and disability pensions among female assembly workers. $B$ Pålsson, $V$ Horstmann, $R$ G Attewell, K Ohlsson, S Skerfving

\section{Cancer}

Trends in cancer mortality in central European countries: the effect of age, birth cohort and time-period. $T V$ Evstifeeva, $G \mathcal{F}$ Macfarlane, $C$ Robertson

Socioeconomic group, occupation and incidence of breast cancer and genital cancer among women in Denmark. B A Rix, T Skov, E Lynge

Compliance after 17 years of breast cancer screening: factors associated with reattendance for periodic breast screening. W ScafKlomp, F L P van Sonderen, $\mathcal{F} W A$ van den Heuvel

\section{AIDS/HIV}

Experience with and attitudes towards HIV patients among Italian general practitioners. A C Bosio, M Cesa-Bianchi

Public reactions to AIDS in Sweden: less anxiety, less risk taking. $C$ Herlitz, $A$ Strandell Intravenous drug users and AIDS: knowledge, attitudes and behaviour in Calabria, Italy. $M$ Pavia, $A$ Indovino, $C G A$ Nobile, $I F$ Angelillo

\section{Methods}

Severity measurement using a generic instrument: a feasibility study in ambulatory care involving patients with diabetes or asthma. $M$ Eccles, $N$ Steen, A Hutchinson, C Bradshaw, $E$ $\mathrm{McColl}$
The development of patient groupings for more effective management of health care. $H$ F Sanderson, L M Mountney

The development of patient groupings for more effective management of health care: a comment. $\mathcal{F}$ Hofdijk

Assuming independence of risk factor prevalences in simulation models like PREVENT: when are the outcomes seriously biased? $P \mathcal{F}$ van de Mheen, L $\mathcal{f}$ Gunning-Schepers

\section{Commentaries}

Socioeconomic health differences: a commentary. $W W$ Holland Socioeconomic health differences: a reply. $L \mathcal{F}$ Gunning-Schepers, $A$ Gepkens

Perinatal and infant mortality: a worldwide issue: a commentary. C Akukwe

\section{Obituaries}

Book Reviews

Calendar of Events

\section{EUPHA pages}

Information for Authors

\section{6th Interntional Symposium on} Epidemiology and Occupational Risks, 22-24 April 1998, Graz, Austria.

International conference on the role and importance of epidemiological studies in the prevention of and compensation for occupational accidents and diseases. Further information: Allgemeine Unfallversicherungsanstalt, Office for International Relations and Conferences, Adalbert-Stifter-Strasse 65, A-1200 Vienna. Tel: +43133111537.

Fax: +43133111469.

email: presse@auva.or.at.

\section{CORRIGENDUM}

Weich $\mathrm{S}$ et al. Strategies for the prevention of psychiatric disorder in primary care in south London $(\mathcal{F}$ Epidemiol Community Health 1997;51:304-09). There is an error in the legend for figure 1 of this article. The legend for the upper line indicated by squares should read "Reduction of ICSA-11 score to 0 for all attenders", and that for the lower line should read " 1 point reduction in ICSA-11".

\section{BOOK REVIEWS}

Joint Approaches for a Better Old Age: Developing Services Through Joint Commissioning. Richard Poxton (Pp 56; £9.95). London: King's Fund, 1996. ISBN 1-85717-114-4.

Responding to the needs of older people probably remains the biggest challenge facing health and social care, to quote the author himself. This report examines the process of joint commissioning of services by health and local authorities in five contrasting local areas. Much of the work of the project has been recorded in a series of previous King's
Fund papers; the present report draws out the key lessons.

Monitoring the process of service development is a slippery task, especially when a multiplicity of agencies is involved. As the report acknowledges, significant changes will take time, often longer than an individual researcher is able to follow them. So here we have an account of work in process, rather than neatly defined historical episodes.

Poxton presents grounds for modest optimism. Achievements differ in the various localities, but rigorous evaluation of planning initiatives is seldom easy, and short term perspectives may be misleading. The qualities of vision and passion, here identified as essential, are particularly difficult to pin down.

One complication to the success of joint commissioning which the report neglects relatively is that of the different occupational settings of the participants. GPs often point out that social services departments have high staff turnover; their own positions are relatively stable, while allowing them considerable scope in deciding the margins of their job. In a primary care led NHS, their contribution to processes like joint commissioning will be increasingly influential.

$$
\begin{array}{r}
\text { BERNARD INEICHEN } \\
\text { Lecturer in Public Health } \\
\text { Charing Cross and Westminster Medical School, } \\
\text { London }
\end{array}
$$

Epidemiology in Old Age. S Ebrahim and A Kalache (eds). (Pp 436; £59.95) London: BMJ Publishing Group, 1996. ISBN 0-7279-0948-7.

Populations are ageing in almost every country, and this book begins to fill a large void in the literature of health in the elderly. There are 45 chapters with an impressive list of contributors. Two thirds are from the UK and the rest from eight different countries. Many are established authorities on their chosen subject. As Margot Jefferys says in her editorial preface, this should become a standard reference book.

Chapter subjects range well beyond consideration of individual diseases, to encompass, for example, health economics, community care, migration and ethnicity, and iatrogenesis. Its scope aims (and generally succeeds) in being truly international. The editors have succeeded in keeping contributors to a uniform chapter length of about nine pages. They have been less successful in achieving a universal standard of up to dateness. However, given the explosion of knowledge in the past decade, and the ease with which it can be retrieved, this is a serious point. There are dangers ahead too-volumes like this age quickly in matters of detail.

Nevertheless, Epidemiology in Old Age is a splendid achievement. The price is too steep for individuals, but medical libraries will find it of great value. It is extremely well produced with a vivid purple cover. Specialists will find their particular concerns examined in more detail elsewhere, but for those who want to venture into new aspects of geriatric epidemiology, their search begins here.

BERNARD INEICHEN

Lecturer in Epidemiology Charing Cross and Westminster Medical School, London 